\title{
A música para tecla do Padre José Maurício Nunes Garcia (1767-1830)
}

\author{
Mário Marques Trilha \\ https://orcid.org/0000-0001-5956-5311
}

Universidade do Estado do Amazonas, Escola Superior de Artes e Turismo

mariotrilha@gmail.com

SCIENTIFIC ARTICLE

Submitted date: 09 Apr 2019

Final approval date: 03 Sep 2019

Resumo: Este texto tem como próposito apresentar um panorama da música para tecla do Padre José Maurício Nunes Garcia, sua destinação didática ou recreativa, suas influências e origens estéticas e históricas, questões de dedilhados, dinâmicas, citações e auto-citações nos solfejos, lições e fantasias do Compêndio e Método de Pianoforte, problemas de autoria e atribuições na Peça para Piano e Modinhas.

Palavras-chave: José Maurício Nunes Garcia; Solfejos com acompanhamento; Métodos para piano; Modinha; Música brasileira para piano.

\section{THE KEYBOARD WORKS OF FATHER JOSÉ MAURÍCIO NUNES GARCIA (1767-1830)}

Abstract: The aim of this paper is to present an overview of the keyboard music of Father José Maurício Nunes Garcia, his didactical and recreational destination and proposals for its use, his influences, aesthetic origins, fingering problems, dynamic, quotes and self-quotes in the Solfeggi, Lessons and Fantasias of the Compêndio e Método de Pianoforte, autorship and attribuition questions in the Peça para Piano and Modinhas.

Palavras-chave: José Maurício Nunes Garcia; Solfeggi with accompaniment; Piano methods; Brazilian piano music. 


\section{A música para tecla do Padre José Maurício Nunes Garcia (1767-1830)}

Mário Marques Trilha, Universidade do Estado do Amazonas, mariotrilha@gmail.com

\section{Introdução}

A Música para tecla do Padre José Maurício Nunes Garcia está entre o repertório mais antigo de música para tecla no Brasil, que chegou até os nossos dias. Os antecessores conhecidos, até o presente momento, são os Os dez motivos para pianoforte ${ }^{1}$, a marcha em fá maior ${ }^{2}$, e muito provavelmente um minueto a quatro mãos ${ }^{3}$ de Marcos Portugal (1762-1831), compostas no Rio de Janeiro, entre 1811 e 1816, no âmbito das suas obrigações como Mestre de Música de Suas Altezas. Estas peças são as primeiras obras para tecla de autor identificado, compostas no Brasil, as obras de Sigsmund Neukomm (1778-1858) compostas no Rio de Janeiro, entre 1817 e 1821, como a Marche funèbre sur la mort du Compte da Barca (1817) ${ }^{4}$ ou o adagio Les Adieux de Neukomm à ses amis à Rio de Janeiro ${ }^{5}$, e as transcrições de melodias populares brasileiras, adicionadas de um acompanhamento de piano, feitas por Johann Baptist Von Spix (1781-1826) e Carl Friederich Philip Von Martius (1794-1868), compiladas e arranjadas entre 1817 e 1820, tendo sido publicadas, em 1823, na obra Reise in Brasilien ${ }^{6}$. O corpus de música para tecla do Padre Nunes Garcia, que chegou até nós, embora de dimensão relativamente reduzida, é bastante significativo como representante da produção destinada à tecla nos seus primórdios no Brasil. Constitue-se do método de pianoforte, sete solfejos e três modinhas para canto e acompanhamento de pianoforte, e uma peça para piano. Infelizmente nenhuma das obras supracitadas chegaram até nós em manuscritos autográfos, sendo cópias e edições posteriores ao falecimento do compositor.

\footnotetext{
${ }^{1}$ Estas breves peças encontram-se atualmente depositadas na Biblioteca Nacional de Portugal, em Lisboa: Motivos [P-Ln FCR 168.42 . P-Ln FCR 168.43 (aut). P-Ln FCR 168.44 (aut).P-Ln FCR 168.45 (aut) P-Ln FCR 168.46 (aut) P-Ln FCR 168.47 (aut) $P-L n$ FCR 168.48 (aut) $P-L n$ FCR 168.49 (aut) $P-L n$ FCR 168.50 (aut) e $P-$ Ln FCR 168.51 (aut)].

${ }^{2} P-\operatorname{Ln} \mathrm{MM} 245 / / 12$.

${ }^{3} P-\operatorname{Ln} \mathrm{MM} 4807$.

${ }^{4} \mathrm{~F}-\mathrm{Pn} \mathrm{Ms} 13234$.

${ }^{5}$ Edição de N. Simrock, Bonn e Colônia. 1822.

${ }^{6}$ Spix \& Martius: 1823-1831. Reise in Brasilien auf Befehl Sr. Majestät Maximilian Joseph I. König von Baiern in den Jahren 1817-1820 gemacht und beschrieben. 3 Bde und 1 Atlas - Verlag M. Lindauer, München. 1388pp. (Bd. II und III bearb. und hrsg. von C.F.Ph. v. Martius).
} 
Tabela 1 - Fontes da música original para tecla de José Maurício Nunes Garcia:

\begin{tabular}{|c|c|c|c|}
\hline Título da peça & $\begin{array}{l}\text { Data da Cópia ou de } \\
\text { impressão }\end{array}$ & Atual Lugar de Depósito & Dedicatória e Cota \\
\hline $\begin{array}{l}\text { Compendio de Musica \& } \\
\text { Methodo de Pianoforte. Do Sr } \\
\text { Padre Mestre Jozé Mauricio } \\
\text { Nunes Garcia Expressamente } \\
\text { escrito para o Dr Jozé Mauricio e } \\
\text { seu irmão Apolinario em } 1821 .\end{array}$ & $\begin{array}{l}1864 \\
\text { Copista não identificado }\end{array}$ & $\begin{array}{ll}\text { Biblioteca } & \text { Alberto } \\
\text { Nepomuceno. Rio de } & \text { Rio daneiro. UFRJ. RJ }\end{array}$ & $\begin{array}{l}\text { BR-RJan 2609. Para José } \\
\text { Apolinário (posteriormente } \\
\text { conhecido como Dr José } \\
\text { Maurício Nunes Garcia Jr) e } \\
\text { Apolinário José. }\end{array}$ \\
\hline Peça para Piano & $\begin{array}{l}\text { Final do século XIX? } \\
\text { Copista não identificado. } \\
\text { Pertencente ao Visconde } \\
\text { de Taunay. }\end{array}$ & $\begin{array}{l}\text { Instituto do Piano Brasileiro. } \\
\text { Brasília. DF }\end{array}$ & Sem dedicatória. Sem cota \\
\hline Beijo a mão que me condena & $\begin{array}{l}1837 . \quad \text { Editado por } \\
\text { Imprensa de Música de P. } \\
\text { Laforge }\end{array}$ & Biblioteca Nacional do Brasil & $B R-R J n$ mas 255423 \\
\hline $\begin{array}{l}\text { No momento da partida, meu } \\
\text { coração t'entreguei }\end{array}$ & $\begin{array}{l}\text { 1837. Editada por } \\
\text { Imprensa de Música de P. } \\
\text { Laforge }\end{array}$ & Biblioteca Nacional do Brasil & $B R-R J n$ mas559144 \\
\hline Marília si me não amas. & $\begin{array}{l}\text { 1840. Editada por } \\
\text { Imprensa de Música de P. } \\
\text { Laforge }\end{array}$ & $\begin{array}{l}\text { Biblioteca Nacional de España } \\
\text { in Collecção De Modinhas } \\
\text { Brasileiras:Com } \\
\text { Accompanhamento De Piano }\end{array}$ & $E-M n$ Mimo0000690029 \\
\hline
\end{tabular}

\section{José Maurício como instrumentista de tecla}

A excelência do Padre José Maurício Nunes Garcia como instrumentista de tecla é ressaltada em duas fontes coevas: O Padre José Maurício de Visconde de Taunay (1843-1899), e nos Apontamentos sobre a vida e as obras do Padre José Maurício Nunes Garcia de Manuel de Araújo Porto-Alegre (1806-1879).

Taunay ressalta a familiaridade de Nunes Garcia com os instrumentos de tecla desde os primórdios de sua instrução musical: "Consta que, do mesmo modo e desde os mais verdes annos, (José Maurício) improvisava no cravo e no piano" (Taunay 1880). Relata ainda um fato ocorrido na Quinta da Boa Vista, contado em 1870, por "pessoa contemporânea, digna de todo o conceito", que forneceu detalhes sobre o pedido de D. Carlota Joaquina (1775-1830) para que Marcos Portugal avaliasse o valor musical de José Maurício "é notável na música, mas quero o seu juízo" Marcos Portugal, aproveitando-se de um evento no palácio, em presença dos príncipes e da corte escolhe então uma sonata de Franz Joseph Haydn (17321809), para que seja feito um exame de leitura à primeira vista. Para espanto geral, José Maurício executa a obra à perfeição e Marcos Portugal abraça-o, declarando ter no padre carioca "um irmão na arte". Talvez o fato do episódio ter ocorrido seis décadas antes de ter sido contado ao Visconde de Taunay contribua para uma certa mistificação do episódio, de toda a forma corrobora a qualidade de Nunes Garcia como instrumentista:

Obedeceu o artista, e aos primeiros acordes feridos fez-se completo silencio. Começou a Sonata. A principio José Maurício se não claudicou, pelo menos mostrou tibieza e frouxidão na execução. A pouco e pouco, porém, foi-lhe voltando a salvadora calma. Concentrou-se chamou a si toda a energia e, reagindo contra o abalo que the escurecia a vista e Ihe prendia os dedos, foi levando de vencida todas as difficuldades d'aquella 
primorosa obra, já esquecido da côrte e das misérias do mundo, e entregue de corpo e alma ás maravillhosas deduções do insigne allemão, cujas paginas interpretava com expressão e facilidade cada vez mais pronunciadas. D'ahi a instantes também pertenciam elle exclusivamente á grandeza da concepção que ia vivificando de modo todo seu, fazendo tanger dos seus dedos de novo escravos submissos da intelligencia e do sentimento, jorrar bellezas sem conta que em todos os ouvintes infundiam pasmo e indizivel enleio. Muitos, voltados para Marcos Portugal, liam na physionomia do orgulhoso musico a sucessão das impressões que o estavam gradualmente avassalando, physionomia no começo fria, desdenhosa, ironica, logo depois attenta, sorpresa e por fim cheia d'esse entusiasmo expansivo que a alma verdadeiramente artistica não póde occultar e que irrompe com força incoercivel na lealdade dos seus arrebatamentos. José Maurício, porém, nada via. Estava todo com Haydn. No andante deu tal melancolia ao thema dominante, fez por tal forma realçar a phrase melodica que nas composições de Haydn perpassa uma insistente, como indecisa chamma, por sobre torrentes de harmonias encadeadas, arrancou do piano taes vozes tão plangentes e novas- as lágrimas de que fala Mozart- que por toda a sala e contra as regras da etiqueta circulou um sentido bravo. Continha-se, porém, o arbitro supremo de quem tudo dependia, mas quando José Maurício atacou o presto final e, sem discrepar uma nota, com a nitidez de magistral execução, destrinçou os motivos que aos quatro e cinco se travam intimamente n'aquelle estylo fugado de pasmosa riqueza e exuberancia. Marcos Portugal não teve mais mão em si, pôz-se talvez máo grado seu, de pé, e ao morrerem as ultimas e vigorosas notas da sonata, precipitou-se para aquelle que de repente se constituira seu igual e no meio dos apllausos dos principes e da côrte apertou-o nos braços com immensa effusão. -Bellissimo! bradou elle, bellisimo! E's meu irmão na arte; com certeza serás para mim um amigo (Taunay 1880,60$)$.

Manuel de Araújo Porto-Alegre relata que Sigsmund Neukomm, valendo-se da sua autoridade de díscipulo de Haydn, avalia José Maurício Nunes Garcia como o "maior improvisador do mundo", louvou igualmente a sua capacidade de acompanhador ao piano e o talento para reduzir partituras de orquestra e coro ao teclado:

O celebre Neukomm, discipulo de Haydn, que veio para esta côrte como lente de musica quando veio a colonia artistica dirigida por Lebreton para fundar a Academia das Bellas Artes, e que foi victima da parcialidade que invectivava José Mauricio, me disse, em Paris, a proposito do mestre brazileiro, que elle era o primeiro improvisador do mundo. Lamentou a sorte do artista no Brazil, louvou o seu caracter, e apreciou as agonias do autor da famosa missa de Requiem; e a proposito narrou-se o seguinte facto, que no meu regresso á patria foi confirmado pelo cantor Fasciotti, que o testemunhara igualmente. Em uma d'aquellas reuniões que se faziam em casa do marquez de Santo Amaro, fizemos prova de algumas musicas que me chegaram da Europa. Todas as vezes que se tratava de cantar, cedia o piano ao padre-mestre, porque melhor do que elle nunca vi acompanhar. Entre varias phantasias, Fasciotti cantou uma barcarola que foi freneticamente applaudida e repetida. José Mauricio, que estava no piano, como que para descansar, começou a variar sobre o motivo, e com os nossos applausos a crescer e multiplicar-se em fonnosas novidades. Suspensos, e interrompendo a nossa admiração com ovações 
continuas, ali ficamos até que o toque da alvorada nos viesse surprehender. Ah! Os Brazileiros nunca souberam o valor do homem que tinham, valor tanto mais precioso pois que era todo fructo dos seus proprios recursos! E como o saberiam? Eu, o discipulo favorito de Haydn, o que completou por ordem sua as obras que deixara incompletas, escrevi no Rio de Janeiro uma missa, que foi entregue á censura de uma commissão composta d'aquelle pobre Mazziotti e do irmão de Marcos Portugal, missa que nunca se executou, porque não era d'elles. Alguns tempos depois, entrando eu na capella real por acaso, ouvi tocar no órgão umas harmonias que me não eram estranhas; pouco a pouco, fui reconhecendo pedaços da minha desgraçada missa; subi ao coro, e dou com José Mauricio, tendo á vista a minha partitura, e a transpo-la de improviso para o seu orgão (Porto-Alegre 1856, 361).

Além destes relatos biográficos, a figura do Padre Nunes Garcia também foi retrada em outras expressões artísticas, como por exemplo, na pintura, ainda que de forma algo fantasiosa e alegórica por Henrique Bernardelli (1858-1936), no quadro, D. João VI ouvindo o Padre José Maurício ao Cravo ${ }^{7}$, ou por discreta alusão, no caso da literatura, no extraodinário conto Um Homem Célebre de Machado de Assis (18391908).

Despiu-se, enfiou uma camisola, e foi para a sala dos fundos. Quando o preto acendeu o gás da sala, Pestana sorriu e, dentro d'alma, cumprimentou uns dez retratos que pendiam da parede. Um só era a óleo, o de um padre, que o educara, que Ihe ensinara latim e música, e que, segundo os ociosos, era o próprio pai do Pestana. Certo é que lhe deixou em herança aquela casa velha, e os velhos trastes, ainda do tempo de Pedro I. Compusera alguns motetes o padre, era doudo por música, sacra ou profana, cujo gosto incutiu no moço, ou também lhe transmitiu no sangue, se é que tinham razão as bocas vadias, cousa de que se não ocupa a minha história, como ides ver (Machado de Assis 1959, 497).

\section{O Método de Pianoforte CPM $236^{8}$}

É o primeiro método para teclado, de que se tem registro, composto no Brasil. 0 título da obra ${ }^{9}$ nos informa ter sido escrita para os estudos dos filhos de Nunes Garcia, José Maurício e Apolinário. Também fornece o ano da composição: 1821. O manuscrito, atualmente depositado na Biblioteca Alberto Nepomuceno da Escola de Música da UFRJ, é uma cópia tardia, data, muito provavalmente, de 1864, pois apresenta esta data assinalada na página 22, e se refere ao filho mais velho como "Dr. Jozé Maurício". Antecede ao Método de Pianoforte um pequeno compêndio de música, com teoria musical básica, ornamentação e sete solfejos com acompanhamento escrito em oposição à tradição napolitana do

${ }^{7}$ D. João VI ouvindo o Padre José Maurício ao Cravo (sic). Henrique Bernardelli (1858-1932). Segunda metade do século XIX. Pintura, 41 x $51 \mathrm{~cm}$. Óleo sobre madeira. Museu Histórico Nacional (Rio de JaneiroRJ). A cena é algo fantasiosa, embora o título atríbuido pelo Museu mencione um cravo, o instrumento retradado é muito mais semelhante a um pianoforte.

${ }^{8}$ Esta abreviatura refere-se ao trabalho de catalogação feito por Cleofe Person Mattos. Catálogo Temático das Obras do Padre josé Maurício Nunes Garcia. Ministério da Educação e Cultura, 1970.

${ }^{8}$ Br-Rjan 2609. Compendio de Musica \& Methodo de Pianoforte. Do Sr Padre Mestre Jozé Mauricio Nunes Garcia Expressamente escrito para o Dr Jozé Mauricio e seu irmão Apolinario em 1821.

${ }^{9}$ Br-Rjan 2609. Compendio de Musica \& Methodo de Pianoforte. Do Sr Padre Mestre Jozé Mauricio Nunes Garcia Expressamente escrito para o Dr Jozé Mauricio e seu irmão Apolinario em 1821. 
acompanhamento com baixo contínuo. A tradição do acompanhamento utilizando o baixo contínuo está em franco recrudescimento na segunda década do século XIX, fenômeno análogo é igualmente observado em Portugal nos 25 Solfeggi Variati Per Esercitare la Voce a Vocalizzare de Girolamo Crescentini (1762$1846)^{10}$, muito provavelmente compostos com acompanhamento de baixo contínuo, e que na década de 1840 tiveram uma parte de acompanhamento de piano acrescentada por um certo "E.J" à serviço da Lithografia e Armazem de Musica de Valentim Ziegler (fl. 1840), em Lisboa. O próprio filho de Nunes Garcia, o Doutor José Mauricio Nunes Garcia Júnior (1808-1884), nos dá um testemunho da utilidade da instrução musical que recebeu de seu pai, especialmente no que concerne ao canto, narrando uma disputa musical com o castrato Giovanni Francesco Fasciotti (17??-1840):

Tendo meu Pai aula publica de muzica, como creança atirei-me a estudar a artinha q'elle escrevêra e cujo original possuo ainda. O celebre cantor Faciotti ouviou-me huma vez (era eu o 10 soprano d'aula) cantar o Stabat Mater de Hayden, cujo Quando Corpus he d'uma afinaçaõ dificilima e n"aula naõ havia instrumento algum pa sustentar as vozes: afogou-me mto, e quis apostar comigo qm daria huma nota mais aguda. Fizemos ambos escala, passei-lhe 3 notas, e com isto dediquei-me todo á muzica como gre cantor, esquecendo-me da minha educação intellectual, ufano de haver ganho a hum castrado!... Religiozamente educado pelo lado moral, doq' meu Pai naõ se descuidava, eu o tive por preceptor e com mais afinco, desde q' o № D João VI retirou-se pa Portugal, qdo elle ficou entaõ mais cazeiro e socegado ou descançado. He sem duvida pr tal beneficio, $q^{\prime}$ ganhei o habito de rezignar-me facilmte dos revezes da sorte, sem dezesperar doq' Deus póde (Garcia 1950, 4).

O acompanhamento escrito por Nunes Garcia para esses solfejos não é destinado a principiantes ao teclado, os dois primeiros solfejos, em dó maior apresentam oitavas na mão esquerda e acordes e terças paralelas na mão direita. $O$ terceiro, em si bemol maior tem dificuldades analógas. O quarto, em dó maior, acordes na mão direita em contratempo. O quinto, em sol maior, é o que possui o acompanhamento mais interessante, a harmonia em acordes quebrados em sextinas na mão direita. O sexto, em dó maior, apresenta as mesmas dificuldades dos três primeiros. O sétimo, em sol maior, apresenta as mesmas dificuldades do precedente, acrescidas de saltos no baixo e harmonias cromáticas na mão direita.

Tabela 2 - Solfejos com acompanhamento do método de pianoforte

\begin{tabular}{|c|c|c|c|}
\hline Tonalidade & Fórmula de Compasso & Acompanhamento & Parte Vocal \\
\hline Dó maior & $\mathrm{C}$ & $\begin{array}{l}\text { me: oitavas e graus conjuntos. } \\
\text { md: acordes, sextas e terças. }\end{array}$ & $\begin{array}{l}\text { Graus conjuntos em grupos de quatro } \\
\text { notas, percorrendo uma décima, } \\
\text { desde a fundamental até a terça, } \\
\text { ascendente e descente. }\end{array}$ \\
\hline Dó maior & $3 / 4$ & $\begin{array}{l}\text { me: oitavas,graus conjuntos e } \\
\text { arpejos } \\
\text { md: acordes, sextas e terças. }\end{array}$ & $\begin{array}{l}\text { Saltos, graus conjuntos e arpejos, } \\
\text { percorrendo uma décima primeira, } \\
\text { desde a fundamental até a quarta, } \\
\text { ascendente e descente. }\end{array}$ \\
\hline Si bemol maior & $3 / 4$ & $\begin{array}{l}\text { me: graus conjuntos e oitavas. } \\
\text { md: acordes, }\end{array}$ & Tercinas em graus conjuntos e arpejos \\
\hline
\end{tabular}

\footnotetext{
${ }^{10}$ Célebre castrato italiano, que chegou a ser diretor do Teatro de São Carlos, em Lisboa, no início do século XIX.
} 


\begin{tabular}{|c|c|c|c|}
\hline Dó maior & C & $\begin{array}{l}\text { me: progressões de terças em } \\
\text { tempos fortes. } \\
\text { md: acordes em tempos fracos }\end{array}$ & Escalas e arrpejos em ritmo sincopado \\
\hline Sol maior & $2 / 4$ & $\begin{array}{l}\text { me: em arpejos simples } \\
\text { md: em acordes quebrados em } \\
\text { sextinas }\end{array}$ & Sextinas em graus conjuntos e arpejos \\
\hline Dó maior & C & $\begin{array}{l}\text { me: em graus conjuntos saltando a } \\
\text { oitava } \\
\text { md: acordes }\end{array}$ & Escalas em fusas \\
\hline Sol maior & $2 / 2$ & $\begin{array}{l}\text { me: em semínimas com } \\
\text { cromatismos } \\
\text { md: acordes, harmonias cromáticas }\end{array}$ & $\begin{array}{l}\text { Movimento por graus conjuntos com } \\
\text { muitos cromatismos. }\end{array}$ \\
\hline
\end{tabular}

O método está divido em duas partes, cada uma apresentando 12 lições. Nas seis primeiras lições da primeira parte encontram-se as peças mais elementares, apresentando apenas a tonalidade de dó maior. Na seis últimas lições da primeira parte, além de dó maior, também há uma lição em do menor, duas em ré maior e uma em ré menor. As lições da segunda parte são mais exigentes do ponto de vista técnico, e bem mais variadas na abordagem das tonalidades, apresentando todas as tonalidades maiores. Ao final das 24 lições encontram-se seis Fantasias (que abordam distintas formas musicais: Rondó, Ária da Capo e tema e variações) que finalizam o método. Nunes Garcia citou obras de sua autoria, e também de Franz Joseph Haydn (1732-1809) e Giacomo Rossini (1792-1868) no material temático das lições. O sistema de dedilhado por ele apresentado é analógo ao utilizado em Portugal, por autores como Francisco Ignácio Solano (ca.1720-1800), João Domingos Bomtempo (1775-1842) e Marcos e Simão Portugal (1774-ca. 1842). 0 sistema apresenta a particularidade de numerar a mão esquerda de forma idêntica à mão direita, como se fosse uma imagem refletida, no entanto, partindo de dedos diferentes, a referência na mão esquerda é o dedo mínimo como primeiro, e na mão direita o polegar. Esta maneira "invertida" de numerar os dedos ${ }^{11}$ pode ser observada no Novo tratado de musica metrica, e rythmica (Lisboa, 1779) de Solano, nos Elementos de Musica e Methodo de Fortepiano ${ }^{12}$ de Bomtempo e nos dedilhados originais de Marcos Portugal, especialmente nos já mencionados Motivos. Quanto ao dedilhado das escalas observamos a manutenção de uma velha tradição ibérica que remonta ao século XVI, e permanecerá em utilização no nosso universo luso-brasileiro até, pelo menos, as primeiras décadas do século XIX, que é a utilização na mão esquerda do seguinte padrão: 4321 Ascendente e 1234 Descendente, e na mão direita 1234 Ascendente. Esse padrão é descrito por Juan Bermurdo (c. 1510 - c. 1565), na Declaracion de Instrumentos Musicales (1555, LXI) e é mencionado por Correa de Arauxo, na Facultad Organica $(1626,62-64)$ como a terceira possibilidade de dedilhado de uma escala, intitulada Carrera extraordinaria. Este dedilhado, para se tocar as escalas, é o mesmo fornecido por Solano, Bomtempo e José Maurício Nunes Garcia. Curiosamente, os dois primeiros livros de música para tecla impressos em Portugal, Arte Novamente Inventada pera Tãger (Lisboa, 1540) de Gonçalo de Baena (ca. 1480 - posterior a 1540), e Flores de Música (Lisboa, 1620) de Manoel Rodrigues Coelho (ca. 1555 - 1635), não apresentam dedilhados, nem para a escala ou qualquer outra passagem. No entanto, ambos se referem ao fato de ser necessária uma boa postura das mãos no teclado. Gonzalo de Baena salienta que:

\footnotetext{
${ }^{11}$ Desconheço a utilização desta particularidade fora do repertório luso-brasileiro para tecla.

${ }^{12}$ P-Ln. C.I.C. 5. Posterior a 1816.
} 
El poner de los dedos se faze segun necessidad: y la verdad es que assi sean acostumbrados que todos siruan cada uno en sus lugares porque no se pierda lo que pueden seruir. y que no anden vnos altos e otros baxos: dando cada qual muy igual: porque sean los puntes muy conformes: y que toda la melodia suene tanto en vno como en otro. Es de considerar que no deuen los dedos estar mas assentados en sus teclas de quanto a cada vna de las letras conuiene: ni menos. Porque si luego ante de su tiempo se alçan: faltaria el sonido de la consonancia. Y si mas de su tiempo quedaren/sobrarían ${ }^{13}$.

Rodrigues Coelho afirma, no prológo, na sua primeira advertência: "O primeiro que advirto he que se hão de trazer as mãos bem sobre as teclas, por ser assi mais fermoso o tanger: \& de maneira se hão de trazer sobre ellas, que quasi se não se não vejam debaixo das mãos"14.

O método para pianoforte de Nunes Garcia, extremamente bem concebido do ponto de vista técnico e musical é um marco inaugural do gênero no Brasil, malgrado sua importância ainda carece de maior divulgação e contextualização com a sua produção similar nas Américas e Europa.

As seis lições iniciais da primeira parte do método estão na mesma tonalidade, dó maior, e apresentam distintos problemas técnicos: na primeira trata-se de terças e acordes na mão esquerda e acordes quebrados na mão direta; na segunda, acordes quebrados em ambas as mãos; na terceira e quarta lições o problema técnico é o mesmo: melodia acompanhada, na quinta lição terças paralelas na mão direita e esquerda; na sexta lição sextas paralelas. Os problemas técnicos abordados no bloco inicial não são propriamente destinados a principiantes absolutos, já sendo requerido um contato prévio com a escrita para tecla. A sétima lição é a primeira do método a apresentar uma outra tonalidade: ré maior, fazendo uso da tópica de marcha, com melodia na mão direita e acordes na esquerda, forma A B A. Na oitava lição a tonalidade de dó maior regressa, no entanto, é uma peça de dimensão muito maior que as anteriormente apresentadas, melodia acompanhada em stilo cantabile, com uma estrutura de rondó: há um tema em dó maior de oito compassos que será repetido três vezes no decorrer da peça, a segunda seção em lá menor com transição para voltar à dó maior, segue-se uma terceira seção em fá maior (com mudança de armadura indicada), onde o acompanhamento tipo baixo de Alberti dá lugar a acordes quebrados sugerindo uma valsa lenta, embora o stile cantabile não seja abandonado, surge aqui quase um pequeno noturno romântico neste rondó de fatura clássica. Após nova transição a peça se conclui com o tema inicial, apresentando, assim, a forma A B A C A. A nona lição, a primeira em modo menor, é uma auto-citação do Agnus Dei da missa de Requiem de 1816, no entanto, a tonalidade é alterada em relação ao original, que está em ré menor, e na lição em dó menor. Apenas os 23 compassos iniciais são uma redução da missa original, Na versão para tecla o procedimento para a modulação ao relativo maior é distinta da missa, pois no original a secção maior é de apenas oito compassos, ilustrando musicalmente o texto Dona eis Requiem, e na versão para tecla é de doze compassos. No original não ocorre a reexposição da secção $A$ em tonalidade menor, na versão para tecla toda a secção $A$ é resposta e acrescida de uma outra secção $B$ em menor acrescida de Coda. É uma nova versão bastante engenhosa do Agnus Dei, que altera a forma original A B e coda, sobre um pedal de dominante, como transição para o Comunnio, transformando-a em uma peça autônoma e conclusiva em forma A B A B' e coda. Resta ainda a indagação da mudança de tonalidade, qual teria sido o próposito didático da alteração? Possivelmente um ligeiro

\footnotetext{
${ }^{13}$ Baena. Arte novamente inventada[...] f. 6v.

${ }^{14}$ Coelho. Flores de Música f.4r.
} 
incremento da dificuldade técnica, posto que dó menor e o relativo maior, mi bemol, são tonalidades mais exigentes, do ponto de vista técnico, que ré menor e o relativo maior fá, sobretudo para executantes em formação, como eram os filhos do Padre José Maurício em 1821, Apolinário José contava com 14 anos e José Apolinário ${ }^{15}$ com 13 anos. A julgar pela idade de ambos, e também pela escrita das peças no método, não eram iniciantes em máteria musical, mas sim jovens músicos em processo de aperfeiçoamento na arte.

A décima lição apresenta, claramente, a tópica de marcha ${ }^{16}$, regressando à tonalidade de dó maior. Novamente apresenta a forma A B A. Sendo o A em dó maior e a seção B em lá menor, lembrando muito a Aria da Capo. Cleofe Person Mattos (1913-2002) acreditou encontrar nessa lição o tema do hino nacional do Brasil, uma associação que beira a licença poética, pois as semelhanças se limitam ao uso de alguns grupetos na melodia marcial.

Vemos então como se conjugam, em JM, o compositor e o professor. Êsses trechos, concebidos com bom gôsto, são fragmentos de peças suas ou motivos extraídos de compositores de sua preferência. Assim é que vamos encontrar: Rossini, Haydn, Mozart. E podemos, até, deparar com trechos do nosso Hino Nacional, o que não é estranhável, pois aparece em diversas obras suas (Mattos 1970, 335).

Essa lição nos permite aventar a hipótese de ser uma transcrição/adaptação de uma marcha para instrumentos de sopro, quiça do próprio Nunes Garcia. Infelizmente, boa parte da sua música instrumental desapareceu, talvez a marcha em questão fizesse parte dos Doze Divertimentos para instrumentos de sopro de 1817, lamentavelmente desaparecidos. O procedimento de transcrever, para piano, marchas originalmente compostas para sopros ou instrumentos de banda não era novidade no Rio de Janeiro Joanino, Neukomm e Marcos Portugal se utilizaram deste procedimento ${ }^{17}$.

Encerram a primeira parte do método as lições décima primeira e décima segunda, ambas são, novamente, auto-citação do Lux Aeterna da missa de Requiem de 1816. A primeira alterando o modo, que na missa é de ré menor, para ré maior, e a segunda conservando o modo menor original. As duas lições são bastante semelhantes, apresentam forma A B A, divergindo, além do modo, na dimensão da coda, que na décima primeira é de oito compassos e na décima segunda de 22 compassos, talvez a maior dimensão desta coda resida no fato de que as tonalidades menores permitem maior utilização de acordes diminutos e outras dissonâncias. Podemos observar uma progressiva aceleração dos andamentos ao longo das lições, do Moderato, nas seis lições iniciais, até atingir o Allegretto, nas três últimas.

Outra particularidade, encontrada apenas na primeira parte do método, é a presença de lições em tonalidade menor. Das trinta peças do método, apenas duas são em modo menor, e não por casualidade

\footnotetext{
${ }^{15}$ Posteriormente conhecido como José Maurício Nunes Garcia Júnior. Único, entre os cinco filhos, reconhecido pelo Padre Nunes Garcia, em processo datado de 1828, ocasião em que teve o nome alterado. Notável personagem do século XIX brasileiro, primeiro médico negro do Brasil, em 1831, eleito membro da Academia Nacional de Medicina, em 1836. Foi substituto da Secção Cirúrgica da Faculdade de Medicina do Rio de Janeiro e professor honorário da Academia de Belas Artes, correspondente da Academia Real de Ciências de Lisboa, membro do Instituto Histórico e Geográfico Brasileiro, músico e pintor.

${ }^{16}$ A respeito da problemática das tópicas musicais ver The Oxford Handbook of Topic Theory editado por Danuta Mirka.

${ }^{17}$ Respectivamente na marche funèbre sur la mort du Compte da Barca e na Marcha e Paso Doble em fá maior.
} 
auto-citações da missa de Requiem de 1816. As duas lições em modo menor são as únicas, entre as 24 lições, a apresentarem indicação de dinâmica: forte e pianissímo.

Na obra para tecla de Marcos Portugal, concebida maioritariamente com própositos didáticos, só encontramos peças em tonalidades maiores.

Tabela 3 - Doze lições da primeira parte do método de pianoforte

\begin{tabular}{|c|c|c|c|}
\hline Tonalidade & $\begin{array}{l}\text { Indicação de } \\
\text { Andamento }\end{array}$ & $\begin{array}{l}\text { Fórmula de } \\
\text { Compasso }\end{array}$ & Problema Técnico \\
\hline 1. Dó maior & Moderato & $\mathrm{C}$ & $\begin{array}{l}\text { Terças e acordes na mão esquerda, melodia arpejada na mão } \\
\text { direita. }\end{array}$ \\
\hline 2. Dó maior & Moderato & $3 / 4$ & Acordes quebrados em ambas as mãos. \\
\hline 3. Dó maior & Moderato & $2 / 4$ & Terças e acordes na mão esquerda, melodia na mão direita. \\
\hline 4. Dó maior & Moderato & $2 / 2$ & Acordes na mão esquerda, melodia na mão direita. \\
\hline 5. Dó maior & Moderato & $3 / 4$ & Terças paralelas \\
\hline 6. Dó maior & Larghetto & C & Sextas paralelas \\
\hline 7. Ré maior & Sem indicação & C & Acordes na mão esquerda, melodia na mão direita. \\
\hline 8. Dó maior & Andante & $3 / 8$ & $\begin{array}{l}\text { Baixo de Alberti na mão esquerda e melodia cantabile na mão } \\
\text { direita. }\end{array}$ \\
\hline 9. Dó menor & Andantino & $3 / 8$ & $\begin{array}{l}\text { Acordes e arpejos na mão esquerda, figuração rápida e oitavas na } \\
\text { mão direita. }\end{array}$ \\
\hline 10. Dó maior & Allegretto & $2 / 2$ & Acordes na mão esquerda, melodia e grupettos na mão direita. \\
\hline 11. Ré maior & Allegretto & $3 / 8$ & $\begin{array}{l}\text { Tromellbass e acordes na mão esquerda. Notas repetidas acordes } \\
\text { e figurações melódicas rápidas na mão direta. }\end{array}$ \\
\hline 12. Ré menor & Allegretto & $3 / 8$ & $\begin{array}{l}\text { Tromellbass e acordes na mão esquerda. Notas repetidas acordes } \\
\text { e figurações melódicas rápidas na mão direta. }\end{array}$ \\
\hline
\end{tabular}

$\mathrm{Na}$ segunda parte do método; igualmente constítuida por doze lições, foram abordadas todas as tonalidades maiores, dó, ré, mi, fá, sol, lá, si, ré bemol, mi bemol, sol bemol, lá bemol e si bemol. Todas as lições são em forma A B A. A primeira lição, apresenta uma melodia com acompanhamento, arpejos e acordes na mão esquerda, alguns embelezamentos cromáticos na melodia na secção $B$, em lá menor. $A$ segunda lição, em ré menor apresenta características semelhantes a lição precedente. $A$ terceira lição, em mi maior, apresentada uma melodia cantabile com acompanhamento de baixo de Alberti. A quarta lição, em fá maior, apresenta um desenho melódico de cariz Haydniano, que guarda alguma semelhança com a ária Nun beut die Flur do oratório Die Schöpfung,composto entre 1796-98. Essa grande obra de Haydn era muito bem conhecida por Nunes Garcia ${ }^{18}$, que a citou algumas vezes em obras suas, como no Laudate Pueri Dominum arrajado sobre alguns motivos da grande obra da Creação do Mundo do immortal Haydn CPM 79.

A quinta lição, em sol maior, é uma citação de Rossini, evocando na seç̧ão $\mathbf{A}$ um dos temas da abertura do Aureliano in Palmira ${ }^{19}$, estreada no Teatro alla Scala, Milão, em 26 de dezembro de 1813 e novamente

${ }^{18}$ No Allgemeine Musikalische Zeitung de 7 de junho de 1820, um correspondente anônimo informa que Neukomm e José Maurício estão fazendo esforços para montarem a Criação no Rio de Janeiro.

${ }^{19}$ Embora seja frequente a associação desta lição com a abertura do /l Barbieri di Siviglia de 1816. No entanto, parece muito mais provável que o Padre Nunes Garcia tenha citado a versão do Aureliano in Palmira, já que esta ópera foi encenada no Rio de Janeiro em 1820, apenas um ano antes da composição das lições do método. O II Barbieri di Siviglia foi estreado no Rio de Janeiro, em 21 de julho de 1821, no Teatro de São João (Kuhl, 5), também seria possível que a citação se refira à esta abertura, no entanto, 
encenada no Rio de Janeiro em 13 de maio de 1820, no Real Theatro de São João ${ }^{20}$, para a comemoração do aniversário de D. João VI. A sexta lição, em lá maior, é um grande Andante Cantabile, com baixo de Alberti na mão esquerda e melodia na mão direita. A sétima lição, em si maior, é uma citação da sinfonia Surpresa de Haydn, no entanto, o caráter é alterado, mudando a tópica original de Opera Buffa para Stilo Cantabile. A oitava lição, em ré bemol maior, apresenta figurações melódicas em arpejos, lembrando o primeiro tema do primeiro movimento da sonata Op 2 no 1 de Ludwig Van Beethoven (1770-1827) ${ }^{21}$ e, igualmente, o primeiro tema do primeiro movimento da sonata em dó menor KV 457 de Wolfgang Amadeus Mozart (1756-1791) 22. A nona lição, mi bemol maior, apresenta a tópica de caça na secção A e terças paralelas em ritmo de bolero na seç̧ão B. A décima lição, em sol bemol maior, inicia com um exordium apresentando um schema dó-ré- mi, com o seu contraponto dó-si- dó, passando para uma melodia acompanhada por acordes quebrados. A lição décima primeira apresenta figurações de tercinas em movimento contínuo na mão direita, fazendo lembrar a seção A do Impromptu Opus 90, D 899 № 2 de Franz Schubert (1798-1828) ${ }^{23}$. A última lição, em si bemol maior, apresenta na seção $A$ uma melodia ornamentada por grupetos e diminuida em semicolcheias, acompanhada por acordes na mão esquerda. A seção B, em sol menor, apresenta a tópica da Marcia Turca ${ }^{24}$, com bastante utilização de cromatismos.

Tabela 4 - Doze lições da primeira parte do método de pianoforte

\begin{tabular}{|c|c|c|c|}
\hline Tonalidade & $\begin{array}{l}\text { Indicação de } \\
\text { Andamento }\end{array}$ & $\begin{array}{l}\text { Fórmula de } \\
\text { Compasso }\end{array}$ & Problema Técnico \\
\hline 1. Dó maior & Moderato & $2 / 2$ & $\begin{array}{l}\text { Arpejos e acordes na mão esquerda, melodia na } \\
\text { mão direita. }\end{array}$ \\
\hline 2. Ré maior & Allegretto & $2 / 2$ & $\begin{array}{l}\text { Terças e acordes na mão esquerda, melodia na } \\
\text { mão direita. }\end{array}$ \\
\hline 3. Mi maior & $\begin{array}{l}\text { Andantino } \\
\text { Moderato }\end{array}$ & C & $\begin{array}{l}\text { Baixo de Alberti na mão esquerda e melodia } \\
\text { cantabile na mão direita. }\end{array}$ \\
\hline 4. Fá maior & Andantino & $6 / 8$ & $\begin{array}{l}\text { Acordes na mão esquerda, melodia na mão } \\
\text { direita. }\end{array}$ \\
\hline 5. Sol maior & Allegretto & C & Acordes na mão esquerda, melodia na mão direita \\
\hline 6. Lá maior & Allegro Maestoso & C & $\begin{array}{l}\text { Baixo de Alberti na mão esquerda e melodia } \\
\text { cantabile na mão direita }\end{array}$ \\
\hline 7. Si maior & Moderato & C & $\begin{array}{l}\text { Baixo de Alberti na mão esquerda e melodia } \\
\text { cantabile em oitavas na mão direita }\end{array}$ \\
\hline 8. Ré bemol maior & $\begin{array}{l}\text { Allegretto } \\
\text { Moderato }\end{array}$ & C & $\begin{array}{l}\text { Acordes na mão esquerda, melodia na mão } \\
\text { direita. }\end{array}$ \\
\hline 9. Mi bemol maior & $\begin{array}{l}\text { Allegretto } \\
\text { Moderato }\end{array}$ & C & $\begin{array}{l}\text { Acordes e arpejos na mão esquerda, figuração } \\
\text { rápida e oitavas na mão direita. }\end{array}$ \\
\hline
\end{tabular}

parece mais crível, pela data, que tenha sido a abertura do Aureliano in Palmira a referência do Padre Nunes Garcia.

${ }^{20}$ Gazeta Extraordinária do Rio de Janeiro. Segunda-feira 15 de março de 1820.

${ }^{21}$ Composta em 1795, em Viena, dedicada a Joseph Haydn.

${ }^{22}$ Composta em 1784, em Viena, dedicada a Theresia Von Trattner.

${ }^{23}$ Embora os improvisos de Schubert tenham sido compostos em data posterior ao método, em 1827. Apenas destaco algumas semelhanças da escrita pianística da época. Talvez explicável pelo Zeitgeist musical das primeiras décadas do século XIX.

${ }^{24}$ Neukomm compôs uma Marcia Turca no seu período carioca, em 1819, o Allegro Alla Turca, terceiro movimento da sua Sonate pour le Pianoforte avec accompagnement de violon. Coincidentemente, na mesma tonalidade, sol menor, escolhida por Nunes Garcia para esta seção. 


\begin{tabular}{|llll|}
\hline 10. Sol bemol maior & $\begin{array}{l}\text { Allegretto } \\
\text { Moderato }\end{array}$ & $\mathrm{C}$ & $\begin{array}{l}\text { Acordes na mão esquerda, melodia em sextas e } \\
\text { terças paralelas na mão direita. }\end{array}$ \\
\hline 11. Lá bemol maior & Allegretto & $3 / 4$ & $\begin{array}{l}\text { Acordes na mão esquerda. Figurações melódicas } \\
\text { rápidas na mão direta. }\end{array}$ \\
\hline 12. Si bemol maior & $\begin{array}{l}\text { Allegretto } \\
\text { Moderato }\end{array}$ & $2 / 4$ & $\begin{array}{l}\text { Acordes na mão esquerda, melodia na mão } \\
\text { direita. }\end{array}$ \\
\hline
\end{tabular}

A terceira, e última parte do método, apresenta peças intituladas "Fantazias", são seis peças, todas em tonalidades maiores: dó, fá, sol, dó, ré e dó. A primeira e segunda fantasias, respectivamente em dó e fá maior estão concebidas na forma Aria da Capo. A terceira fantasia, em sol maior é uma breve peça com melodia repleta de embelezamentos cromáticos, novamente rementendo ao gosto Rossiniano. A quarta fantasia é um rondó A B A C A, com o A em dó maior, B em sol maior e $C$ em lá menor. A quarta fantasia em ré maior, é novamente uma peça breve, alterna as dinâmicas forte e piano evocando passagens soli e tutti, esta fantasia e a segunda são as únicas que apresentam indicação de dinâmica. A sexta fantasia é descrita pelo autor como Thema e 5 Variacões, no entanto, a forma é um Rondó A B A C A D A E A, o A em dó maior, o $B$ em mi menor, o $C$ em lá menor, o $D$ em fá maior e o $E$ em sol maior. A utilização de várias tonalidades e alterações são quase um resumo das dificuldades técnicas apresentadas ao longo do método. A ambiguidade formal entre tema com variações e rondó apresenta semelhança com as Six Variations sur la Danse d'Hutin, composta pelo irmão de Marcos Portugal, Simão Vitorino Portugal, editadas em Lisboa, em 1804, única obra para piano solo impressa em Portugal na primeira década do século XIX. ${ }^{25}$

Tabela 5 - Fantazias

\begin{tabular}{|c|c|c|c|}
\hline Tonalidade & $\begin{array}{l}\text { Indicação de } \\
\text { Andamento }\end{array}$ & $\begin{array}{l}\text { Fórmula de } \\
\text { Compasso }\end{array}$ & Problema Técnico \\
\hline 1. Dó maior & Moderato & $\mathrm{C}$ & $\begin{array}{l}\text { arpejos e acordes na mão esquerda, melodia em oitavas na mão } \\
\text { direita. }\end{array}$ \\
\hline 2. Fá maior & Moderato & $\mathrm{C}$ & $\begin{array}{l}\text { Terças e acordes na mão esquerda, Acordes e melodia na mão } \\
\text { direita. }\end{array}$ \\
\hline 3.Sol maior & Moderato & $\mathrm{C}$ & Acordes esquerda e melodia cantabile na mão direita. \\
\hline 4.Dó maior & Moderato & $\begin{array}{l}\text { Sem indicação. (No } \\
\text { entanto a divisão } \\
\text { dos compassos é } \\
2 / 4 \text { ) }\end{array}$ & Acordes na mão esquerda, Figurações rápidas na mão direita. \\
\hline 5.Ré maior & Allegretto & $\mathrm{C}$ & $\begin{array}{l}\text { Acordes e terçasna mão esquerda, melodia e notas duplas na } \\
\text { mão direita }\end{array}$ \\
\hline 6. Dó maior & Allegro Maestoso & $2 / 4$ & $\begin{array}{l}\text { Baixo de Alberti na mão esquerda e melodia cantabile na mão } \\
\text { direita }\end{array}$ \\
\hline
\end{tabular}

\section{Peça para Piano CPM 235}

O manuscrito não possue data, segundo Cleofe Person de Mattos remonta ao final do século XIX, e seria pertencente ao acervo da família Taunay. Já o pianista e pesquisador, Alexandre Dias, fundador e diretor do Instituto do Piano Brasileiro, afirma que esta fonte estava na posse do musicólogo Aloysio de Alencar

${ }^{25}$ Simão Portugal instalou-se no Brasil em 1811, tornou-se um solicitado professor de piano na corte tropical, é possível que o Padre José Maurício tenha tido acesso à obra referida. 
Pinto (1911-2007), e foi doada ao IPB por Georges Mirault (filho de Aloysio Alencar Pinto). A divergência da informação talvez se explique pela rivalidade entre os dois musicólogos. Alencar Pinto reivindicou, em entrevista concedida ao Correio da Manhã, em 4 julho de 1961, a "redescoberta' do manuscrito do Compêndio de Música e Método de Pianoforte de Nunes Garcia ${ }^{26}$, pois embora tivesse sido mencionado na catalogação de Guilheme de Mello (1867-1932), publicada na Ilustração Musical de 1930, por ocasião da comemoração do centenário da morte de Nunes Garcia, não teria chamado a atenção de nenhum pesquisador antes do próprio Alencar Pinto. A peça em questão, em mi bemol maior, apresenta a indicação de andamento Moderato, em compasso ternário. Seguramente não é um original de Nunes Garcia, tendo, muito possivelmente, sido composta décadas após o falecimento do mesmo. Person de Mattos enxergava aqui "algumas constâncias do compositor" e atribuía uma possível dúvida ao "conceito de autencidade" a eventuais falhas de mémoria do Visconde de Taunay, que executava essa peça "de ouvido", igualmente imputava à "imprecisão de correções" a suspeita de não se tratar de um original do Padre Mestre. A despeito da generosa opinião de Person de Mattos a dúvida não resiste a uma execução ou escuta da obra, se algo guarda da música de Nunes Garcia é uma certa inspiração melódica ${ }^{27}$, estando mais próxima de um noturno ou intermezzo para piano da segunda metade do século XIX.

\subsection{Modinhas Beijo a maõ que me condena (CPM 236), No momento da partida, meu coração t'entreguei (CPM 238) e Marilia si me não amas (CPM 239)}

A primeira obra impressa de Nunes Garcia foi a modinha Beijo a mão que me condena, em fá maior, editada por Pierre Laforge (1791-1853?), em $1837^{28}$. Neste caso, embora a autoria tenha sido contestada antes do catálogo de Person de Mattos, a escrita melódica e, sobretudo, o acampanhamento do piano, tão semelhante a escrita dos solfejos com acompanhamento do método de pianoforte, permitem uma relativa certeza da autoria. A modinha apresenta uma estrura próxima da Cavatina; forma A B, sendo a primeira parte na dominante, sem indicação de andamento, em compasso ternário, e a segunda parte na tônica, em compasso binário, com indicação de Allegro. De toda a forma, na edição de Laforge foi estampado o nome completo do compositor, precedido pelas iniciais: R.S.P.M ${ }^{29}$. Person de Mattos atribuiu a questão da dúvida a "pouca qualidade da peça", bem como uma possível atribuição da modinha ao Dr. Nunes Garcia Jr.

Ao Dr Nunes Garcia, autor da poesia (Trovador, 1876 vol III, p 81), também já foi atríbuida a composição dessa modinha. Na verdade, nada justificaria a dúvida, a não ser a qualidade da peça, que acusa pouco a feitura do Padre Mestre, bem mais "seresteiro" em momentos outros de sua música religiosa (Mattos 1970, 323).

A modinha No momento da partida, meu coração t'entreguei, em si bemol maior, igualmente impressa em 1837, apresenta grandes acordes na mão direita e oitavas na mão esquerda, com uma escrita pianística um pouco distinta da encontrada nos solfejos com acompanhamento do método, no entanto ainda é possível

\footnotetext{
${ }^{26}$ Devo esta informação à Alexandre Dias, a quem agradeço penhoradamente.

${ }^{27}$ Apresenta semelhanças com algumas passagens mauricianas, como, por exemplo, os solos de soprano da Novena da Conceição de Nossa Senhora CPM 64.

${ }^{28}$ O primeiro registro a editora de Pierre Laforge data de 1839 "Pedro Laforge - Rua da Cadeia, 89 estamparia (16/01/1839) No Livro de registros de oficinas de litografia e de gravura (de 1831 a 1891), como se verifica pela data de impressão das duas modinhas, Pierre Laforge já exercia o ofício de editor de música antes do registro oficial.

${ }^{29}$ Reverendo Senhor Padre Mestre
} 
considerá-la como original. Como a modinha precedente é uma forma $A B$, no entanto, sem mudança de fórmula de compasso e alteração de andamento.

A última modinha impressa por Pierre Laforge, em 1840, Marília si me não amas apresenta um acompanhamento distinto das anteriores e pouco semelhante aos acompanhamentos e peças do método, como terças paralelas e oitavas acentuadas na mão direita em tempo fraco, ainda que a lição № 5 da primeira parte do método de pianoforte aborde este problema técnico, a escrita aqui não é exatamente a mesma, talvez indicando uma contribuição ou aggiornamento ao gosto da década de 1840, possivelmente tendo sido o acompanhamento realizado por outro músico, possivelmente o Dr Nunes Garcia Jr. Está estruturada em duas estrofes e estribilho sem seção contraste em outra tonalidade, permanecendo sempre na tônica de ré menor.

Tabela 6 - Modinhas

\begin{tabular}{|c|c|c|c|}
\hline $\begin{array}{l}\text { Título, data de publicação e } \\
\text { Tonalidade }\end{array}$ & $\begin{array}{l}\text { Indicação } \\
\text { Andamento }\end{array}$ & $\begin{array}{l}\text { Fórmula } \\
\text { Compasso }\end{array}$ & $\begin{array}{l}\text { Problema Técnico } \\
\text { acompanhamento }\end{array}$ \\
\hline $\begin{array}{l}\text { 1. Beijo a mão que me condena. } \\
\text { (1837). Fá maior }\end{array}$ & $\begin{array}{l}\text { Sem indicação na } \\
\text { primeira seção. } \\
\text { Allegro na segunda } \\
\text { seção }\end{array}$ & $\begin{array}{l}2 / 4 \text { na primeira } \\
\text { seção } \\
3 / 4 \text { na segunda } \\
\text { seção }\end{array}$ & $\begin{array}{l}\text { Tercinas e acordes na mão direita } \\
\text { direita.cantabile na mão esquerda }\end{array}$ \\
\hline $\begin{array}{l}2 \text { No momento da partida, meu } \\
\text { coração t'entreguei. (1837). Si } \\
\text { bemol maior }\end{array}$ & $\begin{array}{l}\text { Sem indicação de } \\
\text { andamento }\end{array}$ & $6 / 8$ & $\begin{array}{l}\text { Acordes na mão direita e oitavas na mão } \\
\text { esquerda }\end{array}$ \\
\hline $\begin{array}{l}\text { 3. Marilia, si me não amas (1840). } \\
\text { Ré menor. }\end{array}$ & Andante & $2 / 4$ & $\begin{array}{l}\text { Oitavas, acordes e grupetos na mão direita. } \\
\text { Terças paralelas, acordes e oitavas na mão } \\
\text { esquerda. }\end{array}$ \\
\hline
\end{tabular}

\section{Considerações finais}

O pequeno corpus de música para tecla de Nunes Garcia, conservado atualmente, nos permite, a despeito da sua relativa exiguidade, constatar a grande inteligência didática e musical do Padre Mestre. As citações e auto-citações, especialmente as que apresentam uma resignificação do original citado, constituem um campo aberto para a pesquisa da utilização das tópicas em Nunes Garcia. A utilização da tradição ibérica de dedilhados inscreve Nunes Garcia numa linha de pertença estética e histórica da música para tecla da península, o conhecimento e utilização de inflûencias italianas e alemãs demonstram o profundo conhecimento do Padre Mestre da produção européia de seu tempo. Estas 40 breves peças, além de excelente música para propósitos didáticos e artísticos, nos fornecem um microcosmos da produção mauriciana e dos anos iniciais da música para piano no Brasil.

\section{Siglas ${ }^{30}$}

BR-RJn Brasil. Rio de Janeiro, Fundação Biblioteca Nacional, Divisão de Música e Arquivo Sonoro

BR-RJan Brasil, Rio de Janeiro, Biblioteca Alberto Nepomuceno, Escola de Música da UFRJ.

E-Mn Espanha. Madrid. Biblioteca Nacional

F-Pn França, Paris, Bibliothèque Nationale de France

${ }^{30}$ Estas siglas seguem as normas do RISM A/II 
P-Ln Portugal. Lisboa, Biblioteca Nacional, Centro de Estudos Musicológicos

P-Ln C.I.C Colecção Ivo Cruz, Portugal. Lisboa, Biblioteca Nacional, Centro de Estudos Musicológicos

P-Ln FCR Fundo do Conde de Redondo Portugal. Lisboa, Biblioteca Nacional, Centro de Estudos Musicológicos

P-Ln FCN Fundo do Conservatório Nacional. Portugal. Lisboa, Biblioteca Nacional, Centro de Estudos Musicológicos

\section{Referências}

Albuquerque, Maria João Durães. 2006. A Edição Musical em Portugal (1750-1834.) Lisboa: Imprensa Nacional / Fundação Calouste Gulbenkian. Lisboa.

Baena, Gonzalo de. 1540. Arte novamente inventada pera aprender a Tanger. Lisboa: German Galharde.

Bermudo, Juan. 1555. Declaración de Instrumentos Musicales. Osuna: Taller de Juan de Léon.

Bomtempo, Domingos. Elementos de Musica e Methodo de Tocar Pianoforte Manuscrito (anterior a 1816) P-Ln C.I.C 5 .

Cardoso, Lino de Almeida. 2011. O Som Social - Música, poder e sociedade no Brasil (Rio de Janeiro, séculos XVIII e XIX). São Paulo: edição do autor.

Coelho, Manoel Rodrigues. 1620. Flores de Música pera o Instrumento de Tecla e Harpa. Na officina de Pedro Craesbeeck. Lisboa.

Fagerlande, Marcelo. 1995. O Método de Pianoforte de José Maurício Nunes Garcia. Rio de Janeiro: Relume Dumará.

Figueiredo, Carlos Alberto. 2012. José Maurício Nunes Garcia. Verbete. Dicionário Biográfico Caravelas Núcleo de Estudos da Historia da Música Luso-Brasileira.

Garcia Jr., José Maurício Nunes. 1950. “Apontamentos para a noticia biographica do membro correspondente do Instituto Historico e Geographico do Brazil Dr. Jozé Mauricio Nunes Garcia". In: Lange, Francisco Curt. "Estúdios Brasileños". Revista de Estúdios Musicales (1). Mendoza: Universidade Nacional de Cuyo (1-3), p. 176-91.

Kuhl, Paulo Mugayar. 2003. Cronologia da Ópera no Brasil - Século XIX. Rio de Janeiro: Unicamp.

LEME, Mônica 2005. Impressão musical no Rio de Janeiro (SÉC. XIX): modinhas e Lundus para "Iaiás" E "Ioiós (pp. 506-513). ANPPOM.

Machado de Assis, Joaquim Manuel Maria. Obra Completa (II). Rio de Janeiro: José Aguilar, 1962.

Mattos, Cleofe Person de. 1970. Catálogo temático das obras do padre José Maurício Nunes Garcia. Rio de Janeiro: MEC / Conselho Federal de Cultura.

MIRKA, Danuta (org). 2014. The Oxford Handbook of Topic Theory. OXFORD University Press. New York.

Porto-Alegre, Manoel de Araújo. 1856. Apontamentos sobre a vida e a obra do padre José Maurício Nunes Garcia. Revista do Instituto Histórico e Geográfico Brasileiro XIX (354-369). 
Sancta Maria, Tomás de. 1565. Libro llamado Arte de tañer Fantasia assi para Tecla como Vihuela. Valladolid. Edição Fac-similada. In: Denis Stevens. Gregg International Publishers Limited New York, 1972.

Solano, Francisco Inácio. 1779. Novo tratado de musica metrica, e rythmica, o qual ensina a acompanhar no cravo, orgão, ou outro qualquer instrumento...e tratão-se também algumas cousas parciaes do contraponto, e da composição/ por seu author Francisco Ignacio Solano. Lisboa: Regia Officina Typografica.

Correio da Manhã. 4 de junho de 1961. Rio de Janeiro. Disponível em: http://memoria.bn.br/DocReader/DocReader.aspx?bib=089842 07.

Gazeta Extraordinária do Rio de Janeiro. 15 de março de 1820. Rio de Janeiro. Disponível em: http://objdigital.bn.br/acervo digital/div periodicos/gazeta ri/gazeta ri 1820/gazeta ri extra 182 $\underline{0}$ 005.pdf

Taunay, Alfredo d'Escragnolle. 1880. O Padre José Maurício Nunes Garcia. Revista Musical e de Belas Artes.

Trilha, Mário Marques. 2016. "Música para tecla de Marcos Portugal". In: Rocha, Edite (Org.). O cravo na atualidade: ensino, pesquisa e prática (pp. 57-78). Belo Horizonte: Universidade Federal de Minas Gerais. 